\title{
A Systematic Review to Explore the Scope of Interventions to Minimize the Incidence of Congenital Anomalies
}

Saurabh RamBihariLal Shrivastava*, Prateek Saurabh Shrivastava and Jegadeesh Ramasamy

Shri Sathya Sai Medical College \& Research Institute, Kancheepuram, Tamilnadu, India

"Corresponding author: Saurabh RamBihariLal Shrivastava, Department of Community Medicine, Shri Sathya Sai Medical College \& Research Institute, Ammapettai village, Thiruporur-Guduvancherry Main Road, Sembakkam Post, Kancheepuram-603108, Tamil Nadu, India, Tel: +919884227224; E-mail: drshrishri2008@gmail.com

Rec date: July 9, 2014; Acc date: July 23, 2014; Pub date: July 26, 2014

Copyright: (C) 2014 Shrivastava SR, et al. This is an open-access article distributed under the terms of the Creative Commons Attribution License, which permits unrestricted use, distribution, and reproduction in any medium, provided the original author and source are credited.

\begin{abstract}
Congenital anomalies encompasses of structural defects or functional anomalies, present at the time of birth. The objective of this article is to systematically review the published literature on the potential risk factors of congenital anomalies, identify the critical elements in the field of congenital anomalies, and finally suggest wide range of interventions to eventually minimize the incidence of congenital anomalies. An extensive search of all materials related to the topic was made using library sources including PubMed, Medline and Google scholar searches. Keywords used in the search include congenital anomalies, rubella, and global. In conclusion, there is a crucial need to have a sustained political support to ensure development of a holistic policy, targeting all potential risk factors eventually to reduce the incidence of congenital anomalies.
\end{abstract}

Keywords: Congenital anomalies; Rubella; Global; Public health; Screening

\section{Introduction}

\section{Magnitude and impact of congenital anomalies}

Congenital anomalies encompasses of structural defects or functional anomalies, present at the time of birth [1]. The current statistics released by the World Health Organization suggest that one in every 33 infants worldwide suffer from some form of congenital anomaly [2]. In addition, almost a quarter million of neonates eventually die in their neonatal period because of their congenital anomalies [2]. In fact, owing to their global spread, associated social stigma; influence on the quality of life; stress among family members; disability; added medical cost; and overload on the health care delivery system; congenital anomalies have attained a global public health concern [2-5].

\section{Objectives}

The objective of this article is to systematically review the published literature on the potential risk factors of congenital anomalies, identify the critical elements in the field of congenital anomalies, and finally suggest wide range of interventions to eventually minimize the incidence of congenital anomalies.

\section{Material and Methods}

An extensive search of all materials related to the topic was made using library sources including PubMed, Medline, World Health Organization website and Google scholar searches for one month. Relevant documents, technical publications series, systematic reviews, research articles focusing on congenital anomalies published in the period 2008-2014 were included for the review. The identified articles were then re-grouped into different sections viz. potential risk factors; suggested measures, critical elements, and implications for practice. Keywords used in the search include congenital anomalies, rubella, and global.

\section{Potential Determinants}

In spite of extensive research across different nations, for at least fifty percent of the congenital anomalies no conclusive causative/risk factor has been isolated till date [2]. Nevertheless, parameters like advanced maternal age; ethnicity; consanguinity; lower socioeconomic class (enhanced susceptibility to macro/micronutrient malnutrition or infections during antenatal period); existence of chromosomal abnormalities/inborn errors of metabolism; intrauterine infections; teratogenic drugs or pesticides; alcohol/tobacco; malnutrition among mothers (viz. iodine/folate deficiency or diabetes mellitus); and radiation exposure; have been attributed in the causation of congenital anomalies [2,6,7].

\section{Recommended Interventions}

\section{Standard interventions}

Acknowledging the scope of preventive measures in the etiology of the congenital anomalies, there is a definite opportunity to implement primary prevention in different settings. In addition, instituting a comprehensive surveillance mechanism to detect all cases; consolidating the existing public health system; facilitating research to ascertain potential determinants; building linkages with the national and international organizations; can be tried upon to reduce the magnitude of congenital anomalies $[2,8,9]$. However, in absence of a streamlined national program built to counter the congenital anomalies most of the above mentioned interventions cannot achieve the desired results [2]. In addition, there is a definite need to plan and implement customized interventions to bring about an improvement in different dimensions of the individual and ensure development of 
Citation: Shrivastava SR, Shrivastava PS, Ramasamy J (2014) A Systematic Review to Explore the Scope of Interventions to Minimize the Incidence of Congenital Anomalies. Primary Health Care 4: 164. doi:10.4172/2167-1079.1000164

Page 2 of 2

community-based rehabilitation programs for the welfare of society $[1,2]$.

\section{Preventive strategies}

This category generally comprises of measures like improving the range and accessibility of antenatal and post-natal health care amenities; upgrading the nutritional status of the women in reproductive age-group; minimizing exposure to drugs/alcohol/ tobacco/radiation; enhancing vaccination coverage against rubella virus; creating awareness among general population; advocating acceptance of genetic counselling; avoiding the practice of consanguinity or pregnancy at an advanced age; and sensitizing medical practitioners to rule out presence of congenital anomalies $[3,10]$.

\section{Early detection}

Prompt recognition of the anomaly with the help of diagnostic tools like preconception / antenatal screening; employment of prenatal diagnostics (viz. using amniocentesis / chorionic villi sampling/ ultrasound/estimation of alpha-fetoprotein); and new-born screening; can play a defining role in ascertaining the prognosis $[2,7,11]$.

\section{Prompt treatment and rehabilitation}

These modalities of services are recommended to extend medical or surgical options of treatment to correct the obvious structural deformity or biochemical abnormality. In addition, providing psychosocial support and rehabilitation services at the earliest has also been proposed to improve the final prognosis of the disease $[2,3]$.

\section{Implications for Practice}

The findings of the current review clearly reflect the necessity for a comprehensive package of health care services to reduce the incidence of congenital anomalies on a global scale. These services should be formulated based on the identified potential risk factors, well supported by awareness campaigns to spread information about the same that can lead to congenital anomalies. Furthermore, there is a crucial need for the sensitization of the medical practitioners from both the public/private health sector so that they can play an important role in not only early detection but even prevention of the congenital anomalies. Above all, a sustained commitment is needed from the policy makers for supporting the existing maternal and child welfare programs and for establishing a network between different stakeholders to reach to the population residing in low-resource settings.

\section{Conclusion}

In conclusion, there is a crucial need to have a sustained political support to ensure development of a holistic policy, targeting all potential risk factors eventually to reduce the incidence of congenital anomalies.

\section{References}

1. World Health Organization (2014) Congenital anomalies.

2. World Health Organization (2014) Congenital anomalies - Fact sheet N ${ }^{\circ} 370$.

3. Park K (2009) Preventive medicine in obstetrics, paediatrics and geriatrics. In: Park K, Textbook of Preventive and Social Medicine. Banarsidas Bhanot: 496-498.

4. Mashhadi Abdolahi H, Kargar Maher MH, Afsharnia F, Dastgiri S (2014) Prevalence of congenital anomalies: a community-based study in the northwest of iran. ISRN Pediatr 2014: 920940.

5. Garne E, Hansen AV, Birkelund AS, Andersen AM (2014) Major congenital anomalies in a Danish region. Dan Med J 61: A4825.

6. Khanna M, Sarkisian S, Tran P, Ghobrial II (2013) You are never too old for a congenital disease! J Community Hosp Intern Med Perspect 3.

7. Hartofilakidis G, Babis GC (2009) Congenital disease of the hip. Clin Orthop Relat Res 467: 578-579.

8. WHO (2014) National Center on Birth Defects and Developmental Disabilities from the United States Centers for Disease Control and Prevention, International Clearinghouse for Birth Defects Surveillance and Research Birth defects surveillance: A manual for programme managers.

9. Pawluk MS, Campaña H, Gili JA, Comas B, Giménez LG, et al. (2014) Adverse social determinants and risk for congenital anomalies. Arch Argent Pediatr 112: 215-223.

10. World Health Organization (2014) Training programme on surveillance and prevention of congenital anomalies and preterm births.

11. Evans JA (2014) Multiple congenital anomalies: issues for birth defects surveillance. J Registry Manag 41: 7-12. 